\title{
Microbiota de secreções auriculares de cães isolada no Laboratório de Bacteriologia e Micologia do Instituto de Medicina Veterinária Jorge Vaitsman - Rio de Janeiro, RJ
}

\author{
Microbial flora in the ear of dogs isolated in the Bacteriology and \\ Micology Laboratory at Jorge Vaitsman Veterinary Medicine Institute - \\ Rio de Janeiro, RJ
}

\author{
Danielle da Cruz Bonatto," Ricardo Brustein," Poliana Curvelo Costa de Araújo," \\ Giselia de Aquino Daher, "Kátia de Paula Silva*
}

\begin{abstract}
Resumo
Foi estudada a flora microbiana do conduto auditivo de 114 cães, sendo as amostras coletadas com swabs para exame microbiológico. Os microrganismos mais freqüentemente isolados foram: Staphylococcus epidermidis (33,9\%), Pseudomonas aeruginosa (13,6\%), Streptococcus sp (9\%), Proteus sp (7,9\%), Escherichia coli (6,8\%), Malassezia pachydermatis $(7,3 \%)$, Staphylococcus aureus (5,6\%), Staphylococcus sp (4\%), Pseudomonas sp(4\%), Proteus mirabilis $(3,4 \%)$, Klebsiella sp $(2,8 \%)$ e Citrobacter sp $(1,7 \%)$.
\end{abstract}

Palavras-chave: otite externa; microbiota; bactérias; cães.

O conduto auditivo dos cães e gatos apresenta uma grande variedade de microrganismos que se encontram em equilíbrio com o hospedeiro, desde que não leve a predisposição à inflamação, devido a uma série de fatores diferenciados (Greene, 1990).

Algumas bactérias e fungos, em números relativamente baixos, pertencem à microbiota normal do ouvido externo. Dentre eles, a proliferação de Staphylococcus intermedius e Malassezia pachydermatis, respectivamente, está associada a otites (Lobell et al., 1996). As bactérias que infectam o canal auditivo são Proteus sp, Pseudomonas $s p$, Staphylococcus sp, Streptococcus $s p$, Corynebacterium $s p$, coliformes e difteróides; e fungos como, por exemplo, a Malassezia pachydermatis (comumente isolado de ouvidos sadios e doentes de cães). A ocorrência de estafilococos e estreptococos em ouvidos normais e inflamados é similar, o que sugere serem comensais do canal auditivo externo; outros microrganismos como Proteus spe Pseudomonas $s p$ são raramente isolados na otite externa crônica (Fraser et al., 1970; Little, 1996).

Visando a estudar a flora microbiana do conduto auditivo, foram examinados 114 cães, no laboratório de bacteriologia e micologia do Instituto de Medicina Veterinária Jorge Vaitsman durante o período de janeiro a novembro de 1997. Os animais eram de ambos os sexos, de raças diversificadas, sem terem recebido qualquer tratamento prévio com soluções tópicas e sistêmicas de antibióticos e corticóides. As amos- tras foram coletadas com swabs estéreis e imediatamente encaminhadas ao laboratório para o exame bacteriológico.

a) As amostras eram submetidas, após coloração pelo Gram, ao cultivo em Caldo Cérebro Coração - BHI (DIFCO / 0037-17) e incubando-se a $37^{\circ} \mathrm{C}$ por $24 \mathrm{~h}$.

b) Após o período de incubação realizou-se a confecção de esfregaços corados pelo método de coloração de Gram e, de acordo com a morfologia observada, semeou-se nos meios específicos. Para cocos Gram-positivos (CGP) utilizava-se o caldo para Estreptococos (MERCK/5453), Ágarsangue (DIFCO / 5448) e o Ágar Chapman (DIFCO / 5469), sendo incubados na estufa a $37^{\circ} \mathrm{C} / 24 \mathrm{~h}$. Para o isolamento de bastonetes Gram-negativos (BGN), usou-se o meio EMB (Bio Merrieux / 51331) em placas, sendo incubadas em estufa a $37^{\circ} \mathrm{C}$ por $24 \mathrm{~h}$. A partir de colônias isoladas, passava-se às provas bioquímicas complementares, seguindo-se os critérios propostos por (Carter, 1975).

c) Foram utilizados os kits Bac-Tray I, II e III (DIFCO). O sistema compõe-se de três diferentes conjuntos de provas bioquímicas. Duas destas se destinam à identificação de BGN, oxidase-negativa (enterobactéria ou não) Bac-Tray I e II. O terceiro conjunto foi utilizado para aquelas BGN oxidase-positivas, Bac-Tray III. Cada conjunto do sistema compõe-se de dez diferentes substratos contidos em suporte de poliestireno descartável, proporcionando rápida e fácil inoculação simultânea. A identificação bacteriana está baseada na obtenção de 3, 4 ou 7

"Instituto Municipal de Medicina Veterinária Jorge Vaitsman. Av. Bartolomeu de Gusmão 1120, 24941-160, Rio de Janeiro, RJ, Brasil. 
algarismos derivados dos códigos das combinações bioquímicas obtidas.

d) Para o isolamento de leveduras com características compatíveis com Malassezia pachydermatis, foi coletado material com outro swab estéril e o mesmo foi inoculado no meio Ágar Sabouraud, sendo incubados na temperatura de $37^{\circ} \mathrm{C}$, com leitura procedida através de exame microscópico direto, após sete dias.

Os animais encontram-se em faixas variáveis de idade. Até 1 ano foram observados 9 casos positivos (7,9\%); de 1 ano até 7 anos, 65 positivos (55,3\%); acima de 7 anos, 39 positivos (33,3\%); e, sem idade definida, 4 positivos $(3,5 \%)$, o que se assemelha aos dados descritos por Magalhães et al. (1985).

De acordo com o Quadro 1, os microrganismos isolados foram: Staphylococcus epidermidis - 33,9\%, Pseudomonas aeruginosa-13,6\%, Streptococcus $s p-$ $9 \%$, Proteus sp $-7,9 \%$, Escherichia coli $-6,8 \%$,

Quadro 1: Relação percentual dos microrganismos isolados de secreções auriculares em cães

\begin{tabular}{|l|c|}
\hline \multicolumn{1}{|c|}{ M icrorganismo } & $\%$ \\
\hline Staphylococcus epidermidis & 33,9 \\
\hline Pseudomonas aeruginosa & 13,6 \\
Streptococcus sp & 9 \\
\hline Proteus sp & 7,9 \\
\hline Escherichia coli & 6,8 \\
\hline Malasseziapachyderm atis & 7,3 \\
\hline Staphylococcus aureus & 5,6 \\
\hline Staphylococcus sp & 4 \\
\hline Pseudomonas sp & 4 \\
\hline Proteus mirabilis & 3,4 \\
\hline Klebsiella sp & 2,8 \\
\hline Citrobactersp & 1,7 \\
\hline
\end{tabular}

Malassezia pachydermatis - 7,3\%, Staphylococcus aureus - 5,6\%, Staphylococcus sp - 4\%, Pseudomonas $\mathrm{sp}-4 \%$, Proteus mirabilis-3,4\%, Klebsiella sp $-2,8 \%$, e Citrobacter sp - 1,7\%. Em 44,7\% dos exames foi verificada a presença de um agente patogênico. Na maioria dos casos houve associação de mais de dois agentes, $41,2 \%$ com dois microrganismos e $8,8 \%$ com três microrganismos. Já em $5,3 \%$ dos exames não houve crescimento de bactérias nos meios semeados. Os microrganismos freqüentemente isolados nas amostras coletadas são os seguintes: Staphylococcus epidermidis $(28,9 \%)$, Pseudomonas aeruginosa (15,8\%) e Malassezia pachydermatis $(5,5 \%)$ dados estes semelhantes aos encontrados por Fraser et al.; 1970; Langoni et al.; 1991; Lobell et al.; 1996; Nobre et al.; 1997.

Para alguns microrganismos isolados não foi possível determinar a espécie, devido ao laboratório não apresentar todos os meios específicos necessários para a identificação.

Vale ressaltar que, normalmente, as oto-soluções disponíveis para o tratamento das otites não contêm princípio ativo medicamentoso contra a Malassezia pachydermatis, sendo, muitas vezes, responsável pelo insucesso na terapêutica de otites agudas, tornando-as crônicas. O que pode ocorrer também é a instalação de otite primária por um agente bacteriano qualquer, como, por exemplo, estafilococos ou estreptococos, e nestes casos, a inflamação e produtos de secreção local tornarem-se ambiente propício para a multiplicação da Malassezia, presente no conduto auditivo, agravando o quadro de otite, tornando-a crônica (Langoni et al., 1991). Recomenda-se para o tratamento das otites externas, sempre que possível, realizar um exame microbiológico da secreção do ouvido afetado para se pesquisar a presença de bactérias, leveduras e demais agentes patogênicos, a fim de reduzir a resistência dos mesmos aos diversos antibióticos comercializados para uso terapêutico.

\begin{abstract}
The microbial flora from the ears of 114 dogs with otitis externa has been studied, where swab samples were collected to the microbiological exam. The microrganisms more frequently isolated were: Staphylococcus epidermidis (33,9\%), Pseudomonas aeruginosa (13,6\%), Streptococcus sp (9\%), Proteus sp (7,9\%), Escherichia coli (6,8\%), Malassezia pachydermatis (7,3\%), Staphylococcus aureus (5,6\%), Staphylococcus sp (4\%), Pseudomonas sp (4\%), Proteus mirabilis $(3,4 \%)$, Klebsiella sp (2,8\%) and Citrobacter sp $(1,7 \%)$.
\end{abstract}

Keywords: otitis externa; microbial; bacteria; dogs.

\section{Referências bibliográficas}

CARTER, G. R. Diagnostics Procedures in Veterinary Microbiology, 2nd ed.; Springfield, Charles \& Thomas, 301 p., 1975.
FRASER, G., GREGOR, W. W., MACKENZIE, C. P. et al. Canine ear disease. J Small Animal Prat., v. 10, p. 725-754, 1970.

GREENE, C. Infectious Diseases of the Dog and Cat, p 971. WB. Saunders Company, Philadelphia, 1990. 
LANGONI, H., LISTONI, F. J., FESSEL, Y. M. et al. Microflora aeróbica de ouvido de cães sem otite. Arq Bras Med Vet Zootec, v. 43, n. 3, p. 255-260, 1991.

LITTLE, C. Clinicians approach to the investigation of otitis externa canina. In pratice, january, p. 9-19, 1996.

LOBELL, R., WEINGARTEN, A., SIMMONS, R. Um novo agente para o tratamento da otite externa canina. Rev $A$ hora veterinária v. 88, n. 1, p. 1-5, 1996.
MAGALHÃES, M. J., SILVA, N., JUNIOR, A. P. M. Otite externa em cães atendidos no Hospital Veterinário da UFMG. Etiologia, freqüência e sensibilidade. Arq Bras Med Zootec, v. 37, n. 4, p. 333-341, 1985.

NOBRE, M., MEIRELES, M., GASPAR, L. F. et al. Malassezia pachydermatis e outros agentes infecciosos em otites externas e dermatites em cães. Resumos do XIX Congresso Brasileiro de Microbiologia (SBM) de 11 a 15 de novembro, Rio de Janeiro, p. 115, 1997. 